\title{
The ambition of the European Respiratory Journal: chapter 4
}

\author{
Marc Humbert ${ }^{1}$, Anh Tuan Dinh-Xuan², Elin L. Reeves ${ }^{3}$, Matthew G. Broadhead ${ }^{3}$ \\ and Neil J. Bullen ${ }^{3}$ \\ Affiliations: 'Service de Pneumologie, University Paris-Sud, Inserm U999, Assistance Publique Hôpitaux de \\ Paris, Hôpital Bicêtre, Le Kremlin-Bicêtre, France. ${ }^{2}$ Service de Physiologie, Paris Descartes University EA \\ 2511, Hôpital Cochin, Assistance Publique Hôpitaux de Paris, Paris, France. ${ }^{3}$ European Respiratory Society \\ Publications Office, Sheffield, UK.
}

Correspondence: Marc Humbert, Service de Pneumologie, Hôpitaux Universitaires Paris-Sud, Assistance Publique Hôpitaux de Paris, 78 rue du Général Leclerc, 94270 Le Kremlin-Bicêtre, France.

E-mail: marc.humbertabct.aphp.fr

0

$@$ ERSpublications

The ERJ: publishing and contextualising the best in respiratory research and practice http://ow.ly/V1Gsd

Already we are more than half-way through the current 5-year editorial cycle of the European Respiratory Journal (ERJ), and as we begin 2016 we again open our first issue of the new year with our annual round up and look to the future.

Traditionally, the ERJ has been founded on exceptionally strong research content, attracting the most important, cutting-edge and novel original material from all over the world, and delivering this content to all corners of the globe; in 2015 alone we will have published 200 original research articles encompassing the full spectrum of respiratory diseases. However, we also increasingly seek to provide context to this material and enhance it as much as possible for our readers with editorial comment and discussion through correspondence. We are proud to see that the Agora section continues to develop, both augmenting our research content with short reports and also framing it with thought-provoking and perceptive correspondence, and hopefully bringing our readers to this notional meeting place so that they can participate in the discussion themselves.

Some particular original research highlights from the past year include reports of clinical trial results from the study of tiotropium and olodaterol fixed-dose combination therapy in chronic obstructive pulmonary disease (COPD) [1], and new results indicating that low-dose corticosteroid use may be associated with reduced 28-day mortality in patients with severe community-acquired pneumonia and septic shock [2]. Our publication of a new action framework for tuberculosis elimination in countries with low tuberculosis incidence has also generated great interest [3]. We also continue to attract the very best review articles, in total 35 were published in various guises in 2015: cutting-edge stand-alone reviews; those that appeared as part of our three excellent ongoing series, on lung physiology, controversies in thoracic oncology and rare pulmonary diseases; and of course those comprising our comprehensive "state of the art" reviews and "back to basics" translational science papers.

Although original research will always be the cornerstone of the ERJ, we would also like to mention the numerous and excellent guideline documents, strategy summaries and task force reports that have been published over the past 12 months, both from the task forces established by the European Respiratory Society (ERS) and those resulting from collaborations between the ERS and colleagues representing other national societies, and which we hope will ensure that the ERJ remains an essential reference for clinicians and scientists the world over. In 2015, we published a diverse selection of task force reports, for example the

Received: Nov 202015 | Accepted: Nov 202015

Conflict of interest: Elin L. Reeves, Matthew G. Broadhead and Neil J. Bullen are employees of the European Respiratory Society.

Copyright @ERS 2016 
joint American Thoracic Society (ATS)/ERS statement on research questions in COPD [4], which sought to summarise and identify the gaps in existing knowledge of the disease, and thus make recommendations for the direction of future research on COPD. A further collaboration between the ATS and ERS resulted in a statement regarding nomenclature and classification criteria for patients with idiopathic interstitial pneumonia and features of autoimmunity. They concluded that the new designation "interstitial pneumonia with autoimmune features" should be used to identify those individuals with idiopathic interstitial pneumonia and features suggestive of, but not definitive for, a connective tissue disease - more clearly defining this subset of patients to hopefully aid their identification and treatment [5].

Further ERS statements also appeared regarding the monitoring of asthma in children [6], smoking cessation techniques for patients with pulmonary diseases [7] and on the diagnosis and treatment of primary spontaneous pneumothorax [8]. In addition to these task force reports, the ERJ also published a white paper on lung cancer screening that was jointly developed by the ERS and the European Society of Radiology [9].

In the September 2015 issue of the journal, we were delighted to publish the outstanding Global Initiative for Asthma (GINA) strategy report, authored by REDDEL et al. [10], which summarised the new GINA roadmap for asthma control.

In August 2015, the ERS and the European Society of Cardiology (ESC) issued the first update in 6 years of their guidelines for the diagnosis and treatment of pulmonary hypertension [11]. The guidelines were published jointly by the ERJ and the European Heart Journal to coincide with the ESC Congress, and will be an indispensable resource for respiratory practitioners and cardiologists for many years to come. Further collaboration in guideline development resulted in the joint publication of the European Society of Gastrointestinal Endoscopy, ERS and European Society of Thoracic Surgeons guidelines on endosonography for the diagnosis and staging of lung cancer in the European Journal of Cardio-Thoracic Surgery, ERJ and Endoscopy Journal [12].

The quality of the articles we publish, be they guidelines, original research, reviews or those from our state of the art and back to basics series, is reflected in the impact factor of the journal, which again rose healthily, by more half a point, over the past 12 months, from 7.125 to 7.636 (fig. 1). This has enabled us to maintain our position ranked at number 4 among respiratory system journals worldwide, despite the addition of Lancet Respiratory Medicine, already ranked at number 2, to an already thriving field of journals in our specialty.

We are also constantly aware that you, our readers and authors, want (and need) access to the content we publish increasingly quickly and conveniently in today's busy world, and in the competitive environments in which we are increasingly asked to work. To this end, we are happy to report that our current publication lag time, that is the time between original research articles being accepted and then being published in their final form in one of our monthly issues, is now down to just 4-5 months. In addition to monthly publication, our research content (both full articles and letters) and reviews are published online first, in near-final PDF version and now with accompanying full-text content, all within approximately 6 weeks of being accepted for publication - and we aim to be quicker in 2016! In fact, just about the only service our "ERJ in press" page does not provide to our readers and to the authors of these articles is a final citation including page and volume/issue numbers. This is why we are considering changing the way in which the ERJ publishes to a "continuous publication" model. In this publication model, a journal does not have an intermediate online-only "in press" publication stage: articles are simply assigned to an issue on first publication, and in doing so are considered published in their final form,

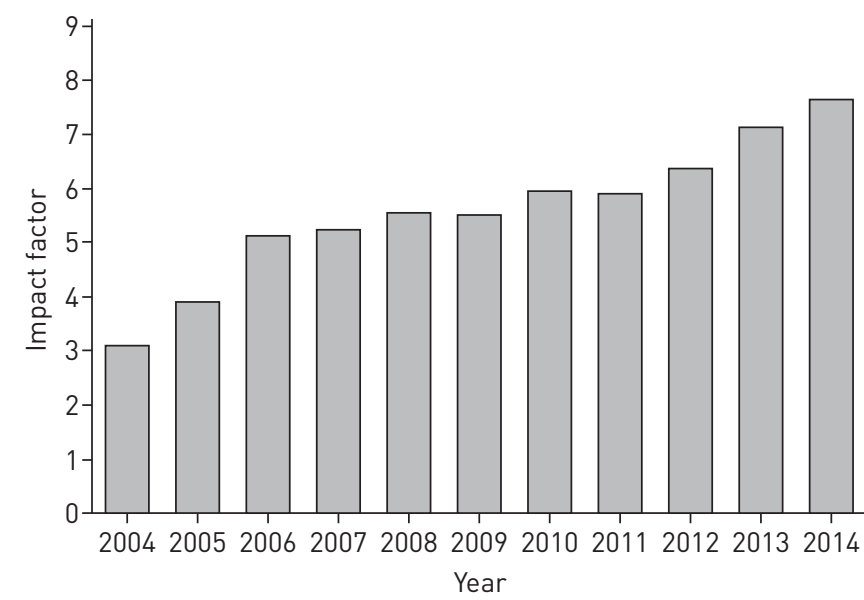

FIGURE 1 European Respiratory Journal impact factor 2004-2014. 
complete with full and permanent citation details, which are immediately available for indexing on platforms such as Web of Science and Medline. An increasing number of journals publish in this manner, recognising the advantages and flexibility that this approach can bring. Although it is true to say that many continuous publication journals are online-only, we would continue to serve our print readership by compiling and printing the ERJ on a monthly basis for those subscribers who still prefer printed material. However, we also look to the future and recognise that our online readership seems to vastly outnumber our print readership; we currently have around 1.3 million unique visitors to our website, looking at more than 8 million pages per year.

The reader need only look to the ERJ's new "sister" journal, ERJ Open Research, to see what a continuous publication journal published by the ERS may look like. Launched in May 2015, with Prof. Anita Simonds of the National Heart and Lung Institute, Imperial College, and the Royal Brompton Hospital, London, UK, as chief editor, ERJ Open Research publishes research from across the respiratory spectrum, under an open access publishing model $[13,14]$.

As ever, the ERJ receives many more submissions than a single journal could possibly publish; in 2015 the number of manuscripts sent to us for review was again far in excess of 2000. This is another reason that we welcome ERJ Open Research into the ERS publications family. With the close relationships forged between the ERJ editorial board, and those of the European Respiratory Review and now ERJ Open Research, along with the greater opportunity now available for publication in the ERS journals, we hope to see the ERS publications reach an even wider readership and further increase the breadth of content over the coming years.

Many of you may have noticed that the ERJ website received a significant makeover in mid-2015. A cleaner, sleeker and less cluttered interface should hopefully provide our readers with a more modern and intuitive platform from which to navigate, discover and read our content. At the same time, increased flexibility and functionality should enable us to look to the future as we continue to develop our online presence in scientific and medical publishing.

Another change we wish to make this year, and another that we hope will be welcomed by authors, is that we will integrate an electronic version of our copyright transfer form with our online submission system. Establishing copyright is an important aspect of publishing in scientific journals, but we also recognise that an abundance of paperwork can be a source of frustration for authors. The new online treatment of copyright forms should help to ease that particular burden somewhat.

The ERJ has also continued to maintain its social media presence, along with the other ERS publications: we play an important role as part of the Society's Facebook and LinkedIn communications, and the publications have their own growing Twitter following. The amount of online traffic resulting from this activity is, for the moment, (relatively) small, but it is growing fast and we feel it is important to remain in this space as it provides an opportunity for informal conversation and debate among colleagues from around the world. Indeed, several of our fellow authors and editors are active on Twitter (if you visit https://twitter.com/ERSpublications/lists/ers-publications-authors/members, we have compiled a list of several of them), and in September 2015, the charity Médecins Sans Frontières used an ERJ paper in their Twitter journal club (https://storify.com/MSFsci/msf-online-journal-club-linezolid-for-the-treatmen), which is organised in order to give their workers in the field worldwide a forum to debate papers in the way that a group of colleagues in a hospital might. Social media also provides an opportunity for authors to discuss their own research, and this is something we would like to encourage: who knows where an idea discovered in an online debate could lead - perhaps even to a publication in the ERJ! With this in mind, we are continuing to encourage authors to bring their work to the widest audience: in 2016 we will revise our authors' guide to gaining exposure for published research, and we are continuing to work with Kudos (www.growkudos.com), a service that provides tools and suggestions for authors who wish to add context to their work, and tools to track discussion of it. And, of course, the ERS publications and communications staff are always ready to assist and advise.

Another change you will see introduced over the course of 2016 is our response to the transition toward transparency and data sharing. It is becoming more common that general medical journals require authors to make their raw data, in particular datasets obtained from clinical trials, publicly available for examination by readers and other researchers. In addition, funding bodies are also beginning to recognise the advantages this approach has for them and increasingly seek to mandate the public archiving of data obtained through research they have supported. As a specialty journal, we do not feel that we should immediately begin to mandate that our authors make their raw data available to other parties. However, we will soon have in place the means to facilitate data sharing for those authors who want to publicly archive their data, or those who are required to do so by the body funding their research. As with all new initiatives surrounding scientific publishing, we will keep our eye on how the policies of journals and funders evolve over time, and respond accordingly. 
As ever, the success of a journal is hugely dependent on the large number of hard-working, diligent peer reviewers, and we gratefully thank all of you who have undertaken reviewing for the journal. It is traditional that we acknowledge our peer reviewers with the publication of their names on the ERJ website, but in additional recognition of their achievements, in 2015 we also asked the (equally hard-working) board of associate editors to nominate the peer reviewers who had completed especially comprehensive and/or numerous reviews over the previous year. Many were nominated, but three outstanding contributors were finally chosen to attend the ERJ editorial board dinner at the ERS International Congress in Amsterdam, and were presented with certificates to recognise their achievements: congratulations to Miguel Angel Martínez-Garcia (Polytechnic and University La Fe Hospital, Spain), Jane S. Lucas (University of Southampton, UK) and Christopher J. Ryerson (University of British Columbia, Canada). In addition for 2016, with the help of our board of associate editors, we also hope to augment our peer review processes by launching a junior mentoring programme. This initiative will be primarily aimed at younger researchers who wish to gain experience of the practical duties and responsibilities of scientific editorship. The scheme will see each entrant paired with an associate editor, and then prepare critical reports, summarise and evaluate peer review comments and shadow the peer review process.

In addition to the peer reviewers, we also would like to warmly thank everyone else whose hard work helps continue the success of the ERJ: the associate editors, the international advisory and editorial boards, and, of course, the authors who contribute their work and those who read it. We wish you all the best for the new year and look forward to working in partnership with you in 2016.

\section{References}

1 Buhl R, Maltais F, Abrahams R, et al. Tiotropium and olodaterol fixed-dose combination versus mono-components in COPD (GOLD 2-4). Eur Respir 2015; 45: 969-979.

2 Tagami T, Matsui H, Horiguchi H, et al. Low-dose corticosteroid use and mortality in severe community-acquired pneumonia patients. Eur Respir J 2015; 45: 463-472.

3 Lönnroth K, Migliori GB, Abubakar I, et al. Towards tuberculosis elimination: an action framework for low-incidence countries. Eur Respir J 2015; 45: 928-952.

4 Celli BR, Decramer M, Wedzicha JA, et al. An official American Thoracic Society/European Respiratory Society statement: research questions in COPD. Eur Respir J 2015; 45: 879-905.

5 Fischer A, Antoniou KM, Brown KK, et al. An official European Respiratory Society/American Thoracic Society research statement: interstitial pneumonia with autoimmune features. Eur Respir J 2015; 46: 976-987.

Pijnenburg MW, Baraldi E, Brand PLP, et al. Monitoring asthma in children. Eur Respir J 2015; 45: 906-925.

7 Jiménez-Ruiz CA, Andreas S, Lewis KE, et al. Statement on smoking cessation in COPD and other pulmonary diseases and in smokers with comorbidities who find it difficult to quit. Eur Respir J 2015; 46: 61-79.

8 Tschopp JM, Bintcliffe O, Astoul $\mathrm{P}$, et al. ERS task force statement: diagnosis and treatment of primary spontaneous pneumothorax. Eur Respir J 2015; 46: 321-335.

9 Kauczor HU, Bonomo L, Gaga M, et al. ESR/ERS white paper on lung cancer screening. Eur Respir J 2015; 46: 28-39.

10 Reddel HK, Bateman ED, Becker A, et al. A summary of the new GINA strategy: a roadmap to asthma control. Eur Respir J 2015; 46: 622-639.

11 Galiè N, Humbert M, Vachiery JL, et al. 2015 ESC/ERS Guidelines for the diagnosis and treatment of pulmonary hypertension. Eur Respir J 2015; 46: 903-975.

12 Vilmann P, Clementsen PF, Colella S, et al. Combined endobronchial and oesophageal endosonography for the diagnosis and staging of lung cancer. Eur Respir J 2015; 46: 40-60.

13 Simonds AK, Reeves EL. ERJ Open Research: FAQs. Eur Respir J 2015; 46: 318-320.

14 Simonds AK. Welcome with Open arms! ERJ Open Res 2015; 1: 00013-2015. 